\title{
Pars plana vitrectomy for primary rhegmatogenous retinal detachment
}

\author{
Stephen G Schwartz \\ Harry W Flynn Jr \\ Department of Ophthalmology, \\ Bascom Palmer Eye Institute, \\ University of Miami Miller School of \\ Medicine, Miami, FL, USA
}

\begin{abstract}
Pars plana vitrectomy (PPV) is growing in popularity for the treatment of primary rhegmatogenous retinal detachment (RD). PPV achieves favorable anatomic and visual outcomes in a wide variety of patients, especially in pseudophakic RD. A growing number of clinical series, both retrospective and prospective, have demonstrated generally comparable outcomes comparing PPV and scleral buckling (SB) under a variety of circumstances. The Scleral Buckling Versus Primary Vitrectomy in Rhegmatogenous Retinal Detachment (SPR) study is a multicenter, randomized, prospective, controlled clinical trial comparing SB versus PPV. This study should provide useful guidelines in the future. At this time, the choice of SB versus PPV should be based on the characteristics of the RD, the patient as a whole, and the experience and preference of the individual retinal surgeon.
\end{abstract}

Keywords: pars plana vitrectomy, rhegmatogneous retinal detachment, scleral buckling

\section{Introduction}

Primary rhegmatogenous retinal detachment (RD) remains an important cause of visual loss (Figure 1). The fundamental principles of retinal attachment surgery are well defined. Specifically, all retinal breaks are identified and treated, and vitreous traction is relieved as part of the surgical strategy. The two most common re-attachment procedures performed today are scleral buckling (SB) and pars plana vitrectomy (PPV) (Schwartz and Flynn 2006). Pneumatic retinopexy (PR) is appropriate for selected superior detachments (Tornambe 1997). Laser demarcation (Vrabec and Baumal 2000) and observation (Brod et al 1995) may be considered in rare circumstances. PPV (Figure 2) is growing in popularity for the treatment of primary RD (SPR Study Group 2003). The current manuscript will review the published literature on the topic and offer guidelines based on the evidence available today.

\section{Theoretical considerations}

Successful retinal attachment surgery requires effective treatment of retinal breaks and relief of vitreoretinal traction (Schwartz and Mieler 2004). Traditionally, SB was considered the procedure of choice for primary RD. SB is the most well-established technique, and has the longest published follow-up data (Schwartz et al 2002). SB has a high single-operation success rate (SOSR) and is considered for many primary retinal detachments, except cases with very posterior breaks and cases in which placing the buckling elements is too technically difficult, such as eyes with thin sclera, prior strabismus surgery, glaucoma drainage devices, etc. Additional relative contraindications to SB alone (without PPV) include giant retinal tear, proliferative vitreoretinopathy (PVR) grade $\mathrm{C}$, and significant vitreous opacity or hemorrhage.

However, PPV is growing in popularity as a first-line procedure for primary RD, especially in pseudophakic patients (Lois and Wong 2003, SPR Study Group 2003). PPV has several advantages over SB (Table 1). Perhaps the major benefit of PPV is 


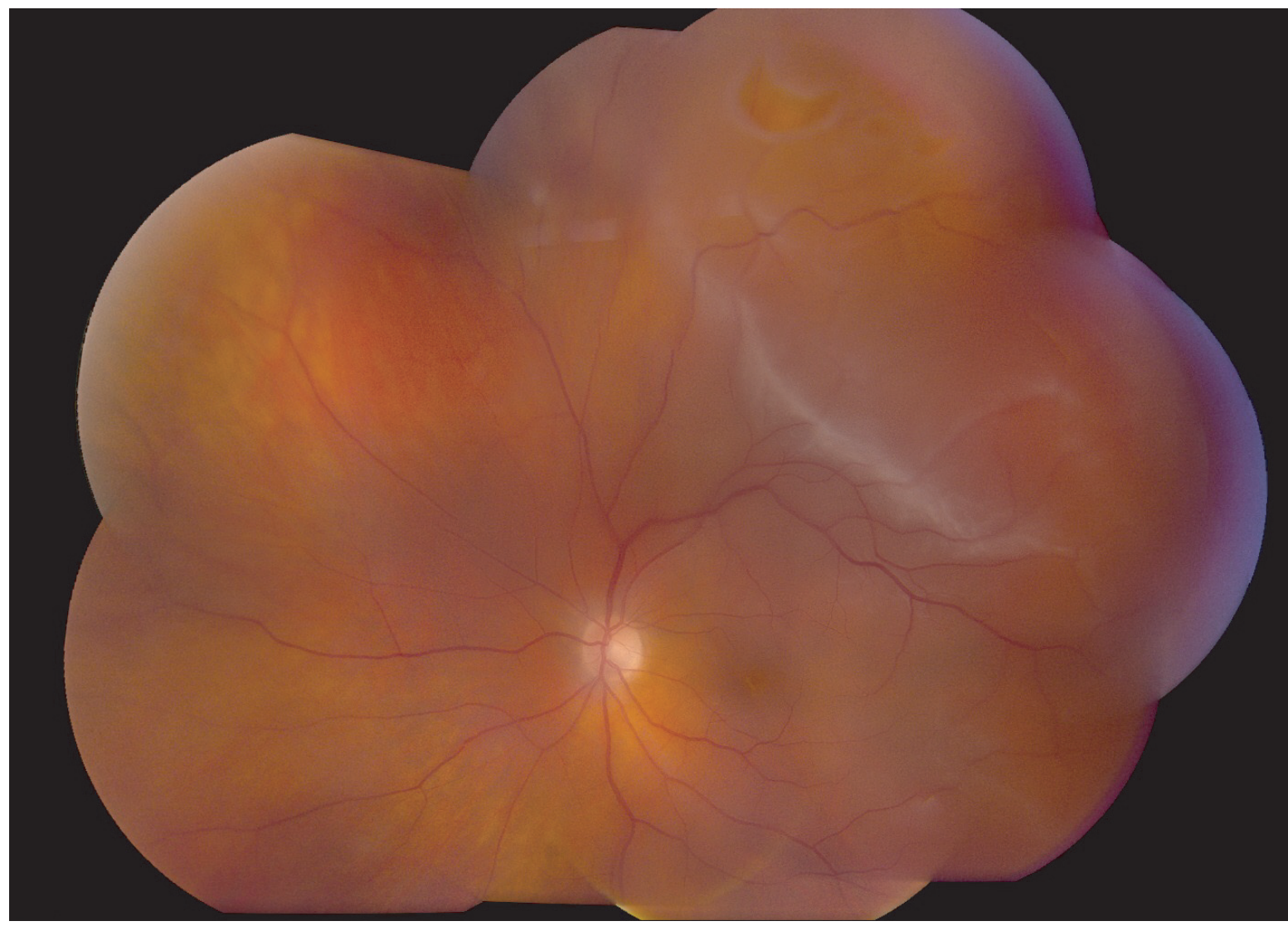

Figure I Primary rhegmatogenous retinal detachment, left eye, with a flap retinal tear at I:00.

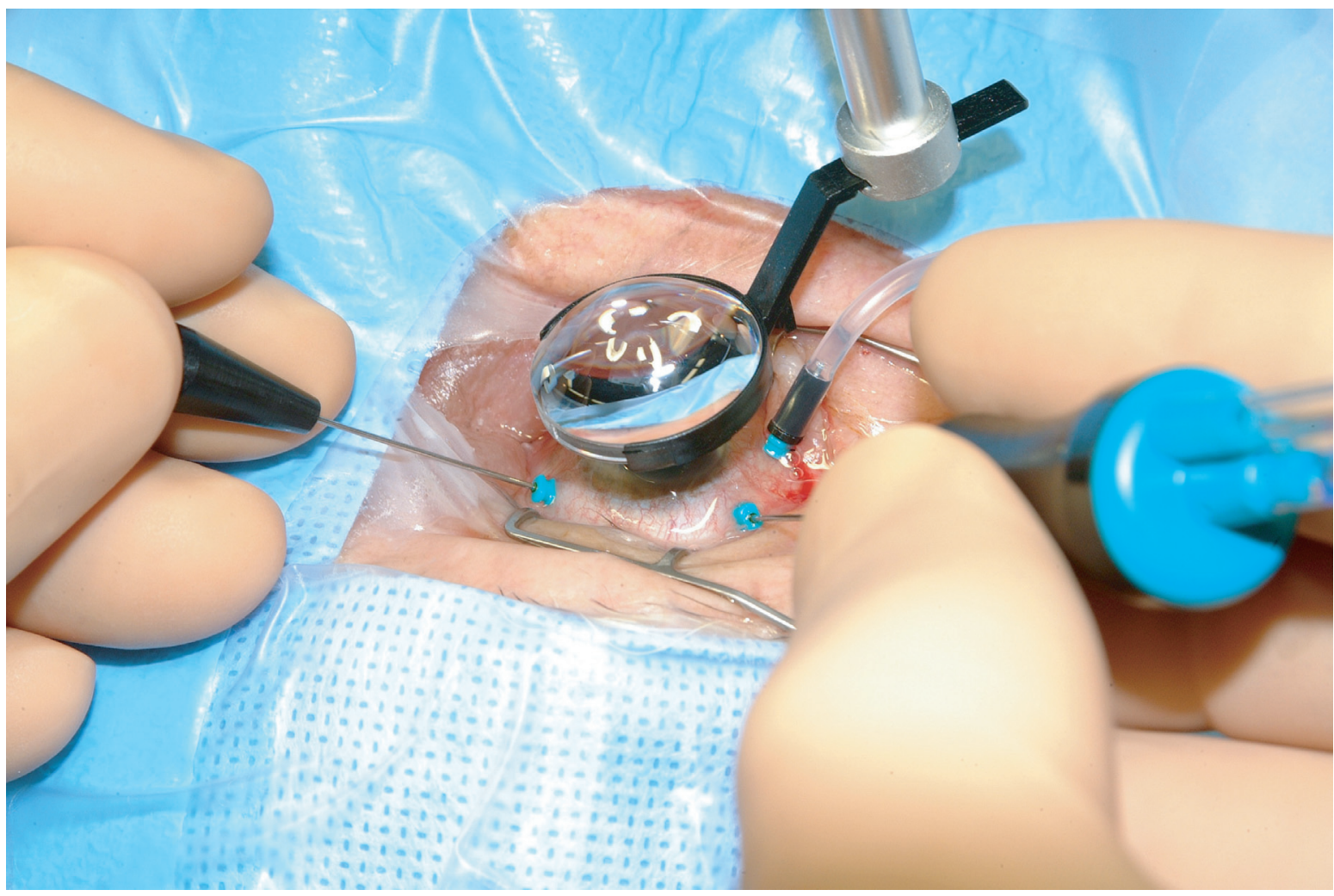

Figure 2 Pars plana vitrectomy (PPV) for rhegmatogenous retinal detachment, utilizing wide-field imaging and small-gauge transconjunctival sutureless instrumentation. 
Table I Pars plana vitrectomy (PPV) versus scleral buckling (SB)

\begin{tabular}{|c|c|c|}
\hline & PPV & SB \\
\hline Visualization of retinal breaks & Generally better & Generally good \\
\hline Relief of vitreoretinal traction & Direct & Indirect \\
\hline \multirow[t]{2}{*}{ Location of retinal break } & More effective for superior & Effective regardless \\
\hline & breaks & of break location \\
\hline Subretinal fluid drainage & Internal & External \\
\hline Post-operative positioning & Generally required & Generally not required \\
\hline Post-operative pain & Generally less & Generally more \\
\hline Surgical costs & Higher & Lower \\
\hline \multirow[t]{4}{*}{ Advantages } & Clears vitreous opacities & Supports “missed” breaks \\
\hline & Giant retinal tears & Allows early air travel \\
\hline & Identification of "missed" breaks & \\
\hline & Faster foveal re-attachment & \\
\hline \multirow[t]{10}{*}{ Potential complications } & New retinal breaks & Refractive change \\
\hline & Elevated intraocular pressure & Motility disturbance \\
\hline & from gas bubble & \\
\hline & Retinal or optic nerve trauma & Retinal or vitreous incarceration \\
\hline & Induced cataract & Migration of buckling elements \\
\hline & Disruption of LASIK flap & Infection of buckling elements \\
\hline & Moisture condensation on silicone & Suprachoroidal or subretinal \\
\hline & IOL during fluid-air exchange & hemorrhage \\
\hline & Retained perfluorocarbon liquids & \\
\hline & Retinal incarceration & \\
\hline
\end{tabular}

Abbreviations: IOL, intraocular lens; LASIK, laser-assisted in situ keratomileusis. Adapted from Schwartz and Flynn (2006).

the potential for an improved view of the retinal periphery, allowing increased identification of retinal breaks. Some authors have advocated the use of transretinal injection of trypan blue (Jackson et al 2007) to facilitate intraoperative localization of retinal breaks. PPV removes vitreous opacities, and allows concomitant cataract surgery or posterior capsulotomy, if necessary to further improve visualization. PPV allows for more controlled drainage of subretinal fluid, either with perfluorocarbon liquids or internal drainage techniques (Brazitikos et al 2003). This may achieve complete intraoperative retinal attachment (particularly important for giant retinal tears) without the risk of hemorrhage or retinal incarceration inherent in external drainage procedures. PPV is unlikely to cause significant motility disturbances, and is frequently less painful than SB. PPV is less likely to cause significant refractive changes than SB in pseudophakic eyes, although some phakic eyes will develop nuclear sclerosis and induced myopia following PPV.

Disadvantages and complications may also occur with PPV for primary retinal detachment (Table 1). PPV increases the risk of new retinal breaks (Al-Harthi et al 2005), cataract formation (Ling et al 2005), and intraocular pressure elevation (Lee et al 2004). If perfluorocarbon liquids are used, they may be retained in the vitreous cavity or subretinal space (Roth et al 2004). Rare complications may include retinal incarceration into a sclerotomy (Stopa and Toth 2006), displacement of a laser in situ keratomileusis (LASIK) flap (Tosi et al 2005), and direct retinal trauma during air-fluid exchange (Yang et al 2006).

PPV is somewhat more technically difficult in phakic patients, because access to the vitreous base is impeded by the crystalline lens. Wide-angle viewing systems and external scleral indentation from a surgical assistant may be helpful (Weichel et al 2006). Perfluorocarbon liquids may be used to stabilize the posterior retina during these maneuvers (Brazitikos et al 2003). Removing peripheral vitreous with 25 gauge vitrectomy instrumentation can be difficult and sometimes impossible. Therefore, many surgeons prefer either 23 gauge or 20 gauge vitrectomy instrumentation for this purpose. In addition, concomitant SB or pars plana lensectomy may be considered.

Traditional teaching held that PPV for primary retinal detachment had too many disadvantages, but recent published case series have called this concept into question. These are summarized in Table 2. PPV without SB was traditionally believed to have a low SOSR in patients with inferior breaks. However, recent series have demonstrated favorable results with PPV for these patients (Sharma et al 2004; Martinez-Castillo, Boixadera, et al 2005; Martinez-Castillo, Verdugo, et al 2005). PPV was traditionally believed to require long-acting intraocular gas 
Table 2 Pars plana vitrectomy: traditional teaching versus current literature

\begin{tabular}{lll}
\hline Clinical variable & Traditional teaching & Newer literature \\
\hline Inferior breaks & $\begin{array}{l}\text { Less effective for patients } \\
\text { with inferior breaks }\end{array}$ & $\begin{array}{l}\text { Favorable } \\
\text { outcomes in these } \\
\text { patients }(\mathrm{I}, 2,3,4)\end{array}$ \\
Gas tamponade & $\begin{array}{l}\text { Importance of long-acting } \\
\text { Fas tamponade }\end{array}$ & $\begin{array}{l}\text { outcomes with air } \\
\text { or short-acting gas } \\
\text { tamponade }(2,3,4)\end{array}$ \\
& & $\begin{array}{l}\text { Favorable } \\
\text { outcomes in } \\
\text { Prone positioning }\end{array}$ \\
& Importance of prone & patients with inferior \\
& positioning & proks without \\
& &
\end{tabular}

\section{References:}

I. Sharma et al 2004.

2. Martinez-Castillo, Verdugo, et al 2005.

3. Martinez-Castillo, Boixadera, et al 2005.

4. Martinez-Castillo et al 2007.

(or silicone oil) tamponade, especially for inferior breaks. However, recent case series have documented generally favorable results using air tamponade or even aqueous tamponade (Martinez-Castillo, Boixadera et al 2005; Martinez-Castillo, Verdugo et al 2005; Martinez-Castillo et al 2007). PPV was traditionally believed to require some degree of face-down positioning for inferior breaks, but a recent case series demonstrated favorable outcomes with very limited positioning requirements (Martinez-Castillo et al 2007).

An alternative approach to inferior, more complex RDs (large and more posterior tears, advanced proliferative vitreoretinopathy, etc.) is the use of intermediate-term, heavier-than-water tamponade agents. Some authors have advocated the use of retained intravitreal perfluorocarbon liquids, either alone or in combination with silicone oil, for post-operative internal tamponade (Rofail and Lee 2005; Asensio-Sanchez et al 2007). The combination of perflurohexyloctane (F6H8) and silicone oil has been advocated by some authors (Rizzo et al 2006). Heavy silicone oil (Oxane HD, Bausch and Lomb, Toulouse, France) also has demonstrated some efficacy (Wolf et al 2003). Neither perfluorohexyloctane nor heavy silicone oil is available for routine clinical use in the United States at this time.

\section{Clinical studies}

The first report of PPV without concomitant SB to treat RD was published in 1985 (Escoffery et al 1985). Since that time, numerous case series have been published (Table 3). In general, the outcomes (SOSR and visual acuity) appear comparable to those achieved with SB for a wide variety of patients. The poorest outcomes were reported in series which contained patients with chronic detachments and evidence of PVR.

Several retrospective series comparing SB, PPV, and/or combined SB/PPV have appeared in the past few years. These series describe a wide variety of clinical situations and are summarized in Table 4. The majority of these series found no statistically significant difference in SOSR among the various procedures. Similarly, visual results were generally comparable.

Table 3 Selected case series of pars plana vitrectomy for rhegmatogenous retinal detachment

\begin{tabular}{|c|c|c|c|c|}
\hline Study & $\begin{array}{l}\text { Number } \\
\text { of patients }\end{array}$ & SOSR & $\begin{array}{l}\text { Visual acuity } \\
\text { outcomes }\end{array}$ & Comments \\
\hline Escoffery et al I985 & 29 & $79 \%$ & $\geq 20 / 50$ in $81 \%$ & Phakic and pseudophakic \\
\hline Campo et al 1999 & 294 & $86 \%-91 \%$ & Median 20/40 & Pseudophakic \\
\hline Speicher et al 2000 & 78 & $94 \%$ & $\geq 20 / 50$ in $87 \%-88 \%$ & Pseudophakic \\
\hline Brazitikos et al 2003 & 22 & $86 \%$ & Median 20/40 & Phakic and pseudophakic \\
\hline Schmidt et al 2003 & 205 & $71 \%$ & $\geq 20 / 50$ in $11 \%$ & Included PVR \\
\hline Sharma et al 2004 & 48 & $81 \%$ & Mean 20/66 & Inferior breaks \\
\hline $\begin{array}{l}\text { Martinez-Castillo, } \\
\text { Verdugo, et al } 2005\end{array}$ & 15 & $93 \%$ & Mean 20/30 & $\begin{array}{l}\text { Inferior breaks, pseudophakic, } \\
\text { air as tamponade }\end{array}$ \\
\hline $\begin{array}{l}\text { Martinez-Castillo, } \\
\text { Boixadera et al } 2005\end{array}$ & 40 & $90 \%$ & Mean 20/33 & $\begin{array}{l}\text { Inferior breaks, pseudophakic, } \\
\text { no facedown positioning }\end{array}$ \\
\hline Heimann et al 2006 & 512 & $71 \%$ & $\geq 20 / 50$ in $48 \%$ & $\begin{array}{l}\text { Included PVR, included } \\
\text { some PPV/SB }\end{array}$ \\
\hline Johansson et al 2006 & 131 & $87 \%$ & Mean 20/80 & Phakic and pseudophakic \\
\hline $\begin{array}{l}\text { Martinez-Castillo } \\
\text { et al } 2007\end{array}$ & 60 & $98 \%$ & Mean 20/59 & $\begin{array}{l}\text { Pseudophakic, aqueous } \\
\text { tamponade }\end{array}$ \\
\hline
\end{tabular}

Abbreviations: PPV/SB, combined pars plana vitrectomy/scleral buckling; PVR, proliferative vitreoretinopathy. Adapted from SPR Study Group (2003) and Schwartz and Flynn (2006). 
Table 4 Selected retrospective comparative trials

\begin{tabular}{|c|c|c|c|c|}
\hline \multicolumn{5}{|l|}{ Number of patients } \\
\hline Study & SB & PPV & SB and PPV & SOSR \\
\hline Oshima et al 2000 & 55 & $47^{*}$ & 0 & Equal (9I\% SB, 9।\% PPV) \\
\hline Miki et al 200I & 138 & $87 *$ & 0 & Equal (92\% SB, 92\% PPV) \\
\hline \multirow[t]{2}{*}{ Roider et al $200 \mathrm{I}$} & 60 & 10 & 30 & Equivalent (98\% SB, 93\% \\
\hline & & & & PPV and SB/PPV combined) \\
\hline \multirow[t]{3}{*}{ Afrashi et al 2004} & 30 & 0 & $22 * *$ & Higher for SB/PPV \\
\hline & & & & (80\% SB, 90\% SB/PPV, \\
\hline & & & & $P=0.00 I)$ \\
\hline \multirow[t]{2}{*}{ Wickham et al 2004} & 0 & 41 & 45 & Equivalent (89\% PPV, \\
\hline & & & & $73 \%$ SB/PPV, $p=0.11$ ) \\
\hline \multirow[t]{2}{*}{ Cheng et al 2006} & 92 & 19 & 0 & Equivalent (85\% SB, 95\% \\
\hline & & & & PPV, no $\mathrm{p}$ value given) \\
\hline \multirow[t]{2}{*}{ Salicone et al 2006} & 26 & 0 & 18 & Equivalent (62\% SB, $72 \%$ \\
\hline & & & & $S B / P P V, p=0.17)$ \\
\hline \multirow[t]{2}{*}{ Weichel et al 2006} & 0 & 68 & 84 & Equivalent (93\% PPV, \\
\hline & & & & $94 \% \mathrm{SB} / \mathrm{PPV}, \mathrm{p}=0.75)$ \\
\hline
\end{tabular}

Abbreviations: PPV, Pars plana vitrectomy; RD, Retinal detachment; SB, Scleral buckling; SOSR, Single-operation success rate.

*In these 2 studies, most patients in the PPV group underwent PPV only; however, a small (unreported) number of patients underwent combined SB/PPV in each study.

** Used silicone oil as the tamponade agent. "Most" patients also underwent SB, but some were PPV only.

Adapted from SPR Study Group (2003) and Schwartz and Flynn (2006).

Similarly, an increasing number of prospective clinical trials are being reported, many of which are randomized. These are summarized in Table 5. Again, the majority of these studies found no statistically significant differences in either SOSR or visual results between the two treatment modalities.

Other literature reviews have reported conflicting results. One meta-analysis of 29 published studies of pseudophakic
RD reported that both PPV and combined PPV/SB were associated with higher SOSRs and better visual acuity outcomes than was SB alone (Arya et al 2006). However, another review of 9 published studies comparing PPV to SB found no statistically significant differences with respect to SOSR or visual results (Saw et al 2006).

Another area of controversy regards risk of postoperative re-detachment and PVR. A recent statistical analysis reported

Table 5 Selected prospective comparative trials

\begin{tabular}{|c|c|c|c|c|}
\hline \multicolumn{5}{|l|}{ Number of patients } \\
\hline Study & SB & PPV & SB and PPV & Results \\
\hline Tewari et al $2003^{*}$ & 20 & 0 & 20 & $\begin{array}{l}\text { Equivalent SOSR }(70 \% \mathrm{SB}, 80 \% \\
\mathrm{SB} / \mathrm{PPV}, \mathrm{p}=0.72) \text {, equivalent vision } \\
\text { (median } 20 / 120 \mathrm{SB}, 20 / 200 \mathrm{SB} / \mathrm{PPV}, \mathrm{p}=0.4 \text { ) }\end{array}$ \\
\hline Ahmadieh et al $2004^{*}$ & 126 & 99 & 0 & $\begin{array}{l}\text { Equivalent SOSR ( } 68 \% \mathrm{SB}, 63 \% \mathrm{PPV}, \\
\mathrm{P}=0.24) \text {, equal vision (mean } 20 / / 82 \mathrm{SB} \text {, } \\
20 / / 82 \mathrm{PPV} \text { ) }\end{array}$ \\
\hline Stangos et al 2004 & 0 & 45 & 26 & $\begin{array}{l}\text { Equivalent SOSR ( } 98 \% \text { PPV, } 92 \% \\
\text { SB/PPV, no P value given), equivalent } \\
\text { vision (improvement } \geq 3 \text { lines in } 60 \% \\
\text { PPV, } 69 \% \text { SB/PPV, no p value given) }\end{array}$ \\
\hline Sharma et al $2005^{*}$ & 25 & 25 & 0 & $\begin{array}{l}\text { Equivalent SOSR }(76 \% \mathrm{SB}, 84 \% \mathrm{PPV} \\
\mathrm{P}=0.48) \text {, better vision with PPV }(20 / 105 \\
\mathrm{SB}, 20 / 7 \mathrm{IPV}, \mathrm{P}=0.034)\end{array}$ \\
\hline Brazitikos et al $2005^{*}$ & 75 & 75 & 0 & $\begin{array}{l}\text { Higher SOSR for PPV }(83 \% \mathrm{SB}, 94 \% \\
\mathrm{PPV}, \mathrm{P}=0.037) \text {, equivalent vision }(20 / 50 \\
\mathrm{SB}, 20 / 43 \mathrm{PPV}, \mathrm{P}=0.26)\end{array}$ \\
\hline
\end{tabular}

* = Randomized trial.

Abbreviations: RD, Retinal detachment; PPV, Pars plana vitrectomy; SB, Scleral buckling; SOSR, Single-operation success rate.

Adapted from Schwartz and Flynn (2006). 
that SB increased the risk of PVR, especially in pseudophakic cases (Rodriguez de la Rua et al 2005), which contrasted an earlier report indicating the reverse (Cowley et al 1989).

At this time, there has been no definitive prospective, randomized, controlled clinical trial comparing SB to PPV, and this question remains unresolved (McLeod 2004). The Scleral Buckling versus Primary Vitrectomy in Rhegmatogenous Retinal Detachment (SPR) study is a European multicenter, randomized, prospective, controlled clinical trial comparing PPV to SB (Heimann 2001). The SPR study may be limited by the fact that a significant proportion of patients in the primary PPV group also received SB. As yet, no results have been published.

\section{Conclusions}

Although PPV was traditionally considered a second-line procedure for rhegmatogenous $\mathrm{RD}$, there is a growing body of evidence that, in certain cases, PPV represents a reasonable primary approach. However, most of the current literature comes from small case series with limited follow-up and other methodological flaws. The upcoming SPR study should provide useful guidelines.

Therefore, in the absence of convincing study data, the choice of procedure for any individual patient should be left to the surgeon's best clinical judgment, taking into account various factors such as the number, size, and position of retinal breaks; the lens status; the patient's expected ability to cooperate with postoperative positioning requirements; available operating room equipment and staff; surgeon preference; and patient preference. By avoiding a regimented approach and adopting an individualized strategy, results of RD surgery may be optimized. Although some patients will not achieve re-attachment after the initial surgery, a variety of surgical techniques are successful in the vast majority of patients.

\section{Support}

Supported in part by NIH center grant P30-EY014801 and by Research to Prevent Blindness, New York, NY, USA.

\section{References}

Afrashi F, Erakgun T, Akkin C, et al. 2004. Conventional buckling surgery or primary vitrectomy with silicone oil tamponade in rhegmatogenous retinal detachment with multiple breaks. Graefes Arch Clin Exp Ophthalmol, 242:295-300.

Ahmadieh H, Moradian S, Faghihi H, et al. 2005. Anatomic and visual outcomes of scleral buckling versus primary vitrectomy in pseudophakic and aphakic retinal detachment. Six-month follow-up results of a single operation. Report no. 1. Ophthalmology, 112:1421-9.

Al-Harthi E, Abboud EB, Al-Dhibi H, et al. 2005. Incidence of sclerotomyrelated retinal breaks. Retina, 25:281-4.
Arya AV, Emerson JW, Engelbert M, et al. 2006. Surgical management of pseudophakic retinal detachments: a meta-analysis. Ophthalmology, 113:1724-33.

Asensio-Sanchez VM, Torreblanca Aguera B, Martinez-Calvo S, et al. 2007. [Deposits of perfluorooctane after prolonged use as a post-operative vitreous substitute.]. Arch Soc Esp Oftalmol, 82:241-3.

Brazitikos PD, Androudi S, D'Amico DJ, et al. 2003. Perfluorocarbon liquid utilization in primary vitrectomy repair of retinal detachment with multiple breaks. Retina, 23:615-21.

Brazitikos PD, Androudi S, Christen WG, et al. 2005. Primary pars plana vitrectomy versus scleral buckle surgery for the treatment of pseudophakic retinal detachment: A randomized clinical trial. Retina, 25:957-64.

Brod RD, Flynn HW Jr, Lightman DA. 1995. Asymptomatic rhegmatogenous retinal detachments. Arch Ophthalmol, 113:1030-2.

Campo RV, Sipperly JO, Sneed SR, et al. 1999. Pars plana vitrectomy without scleral buckle for pseudophakic retinal detachments. Ophthalmology, 106:1811-15.

Cheng SF, Yang CH, Lee CH, et al. 2006. Anatomical and functional outcome of surgery for primary rhegmatogenous retinal detachment in high myopic eyes. Eye, Jul 21 [Epub ahead of print].

Cowley M, Conway BP, Campochiaro PA, et al. 1989. Clinical risk factors for proliferative vitreoretinopathy. Arch Ophthalmol, 107:1147-51.

Escoffery RF, Olk RJ, Grand MG, et al. 1985. Vitrectomy without scleral buckling for primary rhegmatogenous retinal detachment. Am J Ophthalmol, 99:275-81.

Heimann H, Hellmich M, Bornfeld N, et al. Scleral buckling versus primary vitrectomy in rhegmatogenous retinal detachment (SPR study). 2001. Design issues and implications. SPR study report no. 1. Graefes Arch Clin Exp Ophthalmol, 239:567-74.

Heimann H, Zou X, Jandeck C, et al. 2006. Primary vitrectomy for rhegmatogenous retinal detachment. An analysis of 512 cases. Graefes Arch Clin Exp Ophthalmol, 26:1-10.

Jackson TL, Kwan AS, Laidlaw AH, et al. 2007. Identification of retinal breaks using subretinal trypan blue injection. Ophthalmology, 114:587-90.

Johannson K, Malmsjo M, Ghosh F. 2006. Tailored vitrectomy and laser photocoagulation without scleral buckling for all primary rhegmatogenous retinal detachments. Br J Ophthalmol, 90:1286-91.

Ling CA, Weiter JJ, Buzney SM, et al. 2005. Competing theories of cataractogenesis after pars plana vitrectomy and the nutrient theory of cataractogenesis. A function of altered aqueous fluid dynamics. Int Ophthalmol Clin, 45:173-98.

Lee EJ. 2004. Use of nitrous oxide causing severe visual loss 37 days after retinal surgery. Br J Anaesth, 93:464-6.

Lois N, Wong D. 2003. Pseudophakic retinal detachment. Surv Ophthalmol, 48:467-87.

Martinez-Castillo V, Boixadera A, Verdugo A, et al. 2005. Pars plana vitrectomy alone for the management of inferior breaks in pseudophakic retinal detachment without facedown position. Ophthalmology, 112:1222-6.

Martinez-Castillo V, Verdugo A, Boixadera A, et al. 2005. Management of inferior breaks in pseudophakic rhegmatogenous retinal detachment with pars plana vitrectomy and air. Arch Ophthalmol, 123:1078-81.

Martinez-Castillo V, Zapata MA, Boixadera A, et al. 2007. Pars plana vitrectomy, laser retinopexy, and aqueous tamponade for pseudophakic rhegmatogenous retinal detachment. Ophthalmology, 114:297-302.

McLeod D. 2004. Is it time to call time on the scleral buckle? $\mathrm{Br} J$ Ophthalmol, 88:1357-9.

Miki D, Hida T, Hotta K, et al. 2001. Comparison of scleral buckling and vitrectomy for retinal detachment resulting from flap tears in superior quadrants. Jpn J Ophthalmol, 45:187-91.

Oshima Y, Yamanishi S, Sawa M, et al. 2000. Two-year follow-up study comparing primary vitrectomy with scleral buckling for macula-off rhegmatogenous retinal detachment. Jpn J Ophthalmol, 44:538-49.

Rizzo S, Genovesi-Ebert F, Belting C. 2006. The combined use of perfluorohexyloctane (F6H8) and silicone oil as an intraocular tamponade in the treatment of severe retinal detachment. Graefes Arch Clin Exp Ophthalmol, 244:709-16. 
Rodriguez de la Rua E, Pastor JC, Aragon J, et al. 2005. Interaction between surgical procedure for repairing retinal detachment and clinical risk factors for proliferative vitreoretinopathy. Curr Eye Res, 30:147-53.

Rofail M, Lee LR. 2005. Perfluoro-n-octane as a postoperative vitreoretinal tamponade in the management of giant retinal tears. Retina, 25:897-901.

Roider J, Hoerauf H, Hager A, et al. 2001. [Conventional ablation surgery or primary vitrectomy in complicated retinal holes]. Ophthalmologe, 98:887-91.

Roth DB, Sears JE, Lewis H. 2004. Removal of retained subfoveal perfluoro-n-octane liquid. Am J Opthalmol, 138:287-9.

Salicone A, Smiddy WE, Venkatraman A, Feuer W. 2006. Management of retinal detachment when no break is found. Ophthalmology, 113:398-403.

Saw SM, Gazzard G, Wagle AM, Lim J, Au Eong KG. 2006. An evidencebased analysis of surgical interventions for uncomplicated rhegmatogenous retinal detachment. Acta Ophthalmol Scand, 84:606-12.

Schmidt JC, Rodrigues EB, Hoerle S, et al. 2003. Primary vitrectomy in complicated rhegmatogenous retinal detachment. A survey of 205 eyes. Ophthalmologica, 217:387-92.

Schwartz SG, Flynn HW. 2006. Primary retinal detachment: scleral buckle or pars plana vitrectomy? Curr Opinion Ophthalmol, 17:245-50.

Schwartz SG, Kuhl DP, McPherson AR, et al. 2002. Twenty-year follow-up for scleral buckling. Arch Ophthalmol, 120:325-9.

Schwartz SG, Mieler WF. 2004. Management of primary rhegmatogenous retinal detachment. Comp Ophthalmol Update, 5:285-94.

Sharma A, Grigoropoulos V, Williamson TH. 2004. Management of primary rhegmatogenous retinal detachment with inferior breaks. $\mathrm{Br} J$ Ophthalmol, 88:1372-5.

Sharma YR, Karunanithi S, Azad RV, et al. 2005. Functional and anatomic outcome of scleral buckling versus primary vitrectomy in pseudophakic retinal detachment. Acta Ophthalmol Scand, 83:293-7.
Speicher MA, Fu AD, Martin JP, et al. 2000. Primary vitrectomy alone for repair of retinal detachments following cataract surgery. Retina, 20:459-64.

SPR Study Group. 2003. View 2. The case for primary vitrectomy. $\mathrm{Br} J$ Ophthalmol, 87:784-7.

Stangos AN, Petropoulos IK, Brozou CG, et al. 2004. Pars-plana vitrectomy alone vs vitrectomy with scleral buckling for primary rhegmatogenous pseudophakic retinal detachment. Am J Ophthalmol, 138:952-8.

Stopa M, Toth CA. 2006. A method to free retina and vitreous from intraoperative incarceration in the sclerotomy. Retina, 26:1070-1.

Tewari HK, Kedar S, Kumar A, et al. 2003. Comparison of scleral buckling with combined scleral buckling and pars plana vitrectomy in the management of rhegmatogenous retinal detachment with unseen retinal breaks. Clin Exp Ophthalmol, 31:403-7.

Tornambe PE. 1997. Pneumatic retinopexy: the evolution of case selection and surgical technique. A twelve-year study of 302 eyes. Trans Am Ophthalmol Soc, 95:551-78.

Tosi GM, Tilanus MA, Eggink C, et al. 2005. Flap displacement during vitrectomy 24 months after laser in situ keratomileusis. Retina, 25:1101-3.

Vrabec TR, Baumal CR. 2000. Demarcation laser photocoagulation of selected macula-sparing rhegmatogenous retinal detachments. Ophthalmology, 107:1063-7.

Weichel ED, Martidis A, Fineman MS, et al. 2006. Pars plana vitrectomy versus combined pars plana vitrectomy-scleral buckle for primary repair of pseudophakic retinal detachment. Ophthalmology, 113:2033-40.

Wickham L, Connor M, Aylward GW. 2004. Vitrectomy and gas for inferior break retinal detachments. Are the results comparable to vitrectomy, gas, and scleral buckle?. Br J Ophthalmol, 88:1376-9.

Wolf S, Schon V, Meier P, Wiedemann P. 2003. Silicone oil-RMN3 mixture ("heavy silicone oil") as internal tamponade for complicated retinal detachment. Retina, 23:335-42.

Yang SS, McDonald HR, Everett AI, et al. 2006. Retinal damage caused by air-fluid exchange during pars plana vitrectomy. Retina, 26:334-8. 
